The great ingenuity required in devising probable chain mechanism for reactions, such as the photochemical decomposition of hydrogen peroxide or the chlorination of hydrocarbons of the aromatic series, has caused many to reject this conception, originally due to Nernst, and to substitute in its place one of the following hypotheses. According to the "hot molecule" theory of Christiansen and Kramers, the products of a reaction such as

$$
\mathrm{Cl}_{2}^{\prime}+\mathrm{H}_{2}=2 \mathrm{HCl}
$$

must contain not only the original energy of activation but also the energy liberated by the chemical reaction; they are thus more "active" than their neighbours. It is imagined that a "hot" molecule formed in this way may excite another reactant molecule on collision. Again, it may be imagined that this energy, instead of being contained in the products, may be liberated as radiation which is absorbed by the surrounding reactants activating them in turn; this conception has in fact been made even more concrete by the definite conception of a "quantum" chain.

More recently, due to the investigations of Frank and Cario, the scope of the methods of photosensitisation in which an excited molecule can, on collision with a reactant, hand on its energy of activation to it, thus causing subsequent chemical reaction, has been greatly extended by the employment of mercury vapour as sensitising agent. By such means the amount of energy capable of being conveyed in this manner is far greater than with the sensitising agents usually employed, such as molecules of the halogens or the dyes employed in the photographic plate. It is possible that the active nitrogen of Lord Rayleigh $(V=9.5$ volt) may prove an even more powerful conveyer of energy than mercury atoms excited with the line $\lambda_{2537}$. The ready production of atomic hydrogen in this manner has opened up a path by which the properties of the organic radicals, such as ethyl, formed by the reaction may be investigated.

$$
\mathrm{C}_{2} \mathrm{H}_{4}+\mathrm{H} \rightarrow \mathrm{C}_{2} \mathrm{H}_{5}
$$

Whilst these natural processes may be considered at the present time to be capable both of reasonably precise experimental investigation and their real existence capable of being demonstrated, the situation is quite otherwise in certain other, phenomena, an adequate explanation for which is as yet not forthcoming.

It is found that in certain reactions hitherto considered as extremely simple in character, such as the decomposition of ozone, the photochemical efficiency may remain unchanged even for low pressures of the reactant and sensitising agent, chlorine, whilst the presence of indifferent gases exerts a marked influence on the reactant velocity. According to the experiments of Wien, the life of an excited molecule is of the order of $\mathrm{ro}^{-7}$ seconds and metastable forms of active molecules are as yet unknown. Whatever the active species may be in this particular reaction, it is clear that it must have a relatively long life ; furthermore, it can suffer a number of collisions with indifferent gas molecules without losing its energy, this number varying with the nature of the gas. Various explanations, such as the existence of intermediate compounds, the restriction of the reaction to the walls of the vessel and replacing the concept of an excited molecule by an excited atom, have all been advanced on very slender foundation.

Finally, it would appear from consideration of the decomposition of nitrogen pentoxide at very low pressures, that the process of distribution of internal energy amongst these molecules can proceed at a rate much faster than is to be anticipated from the Maxwellian period of molecular relaxation. If, indeed, this process occurs through the agency of radiation, nitrogen pentoxide must be singularly opaque to its own selfgenerated radiation.

It may be anticipated that increased attention will be given to the subject of photochemistry, for it is clear that it opens a door to some of the most interesting and important fields in the region of atom dynamics, a subject on which, in the words of Goethe, we are anxious to have "more light."

ERIC K. RideAL.

\title{
French Contributions to Metallurgy.
}

THE well-known attention which has been devoted to the history of metallurgy by Sir Rohert Hadfield receives an interesting supplement in a paper recently read (Oct. 5) in Paris at a congress of industrial chemistry organised by the French Society of Chemical Industry. The main theme of the address is the interrelation of British and French research in metallurgy, but the aspect, which to most readers will be found of the greatest interest, is the excellent résumé given of the debt which this subject owes to French men of science. As an example, the author pays generous tribute to the importance, in connexion with his own discovery of manganese steel, of the investigations carried out by the Terre Noire Cie. on the commercial production of ferrous alloys very high in manganese.

The paper, which is characterised by the pleasing discursiveness associated with similar lectures which Sir Robert Hadfield has already delivered on metallurgical history, contains, however, nothing more interesting than the photo-micrograph, now published for the first time, of the structure of the iron of the famous Delhi pillar, to which the author has devoted considerable attention. To metallographers interested in the remarkable resistance of this pillar to corrosion this structure shown in Fig. I will be of more than passing interest. The almost complete freedom from slag throws more than a little doubt on the view that a large part in the resistance of wrought iron to corrosion, a fact still awaiting an adequate explanation, is played by inclusions of slag.

The account given of French contributions to metallurgy since the time of Réaumur (I722) is of considerable interest. In the $5^{\circ}$ years which followed, there appeared a number of important metallurgical books in France, of which the titles of 27 are recorded. A brief account is given of the more important contributions to metallurgical knowledge during this period. Among the older names one meets those of Réaumur himself, Berthollet, Vauquelin, the discoverer of chromium, the metal which rendered the production of a rustless steel a possibility, of Berthier

NO. 2922 , VOL. I I 67 
and Le Play. In more recent years the tradition has been carried on by Le Châtelier, Moissan, Pourcel, Osmond, Dumas, and Guillaume, whose work on the special alloys of iron resulted in the discovery of "Invar," an iron-nickel alloy the coefficient of expansion of which at ordinary temperatures is negligible. Such a list shows how keen has been the interest taken by French scientific workers in metallurgical problems. The debt due to them is not readily appreciated, that due to Le Châtelier being even greater than Sir Robert acknowledges, since, in addition to the credit already

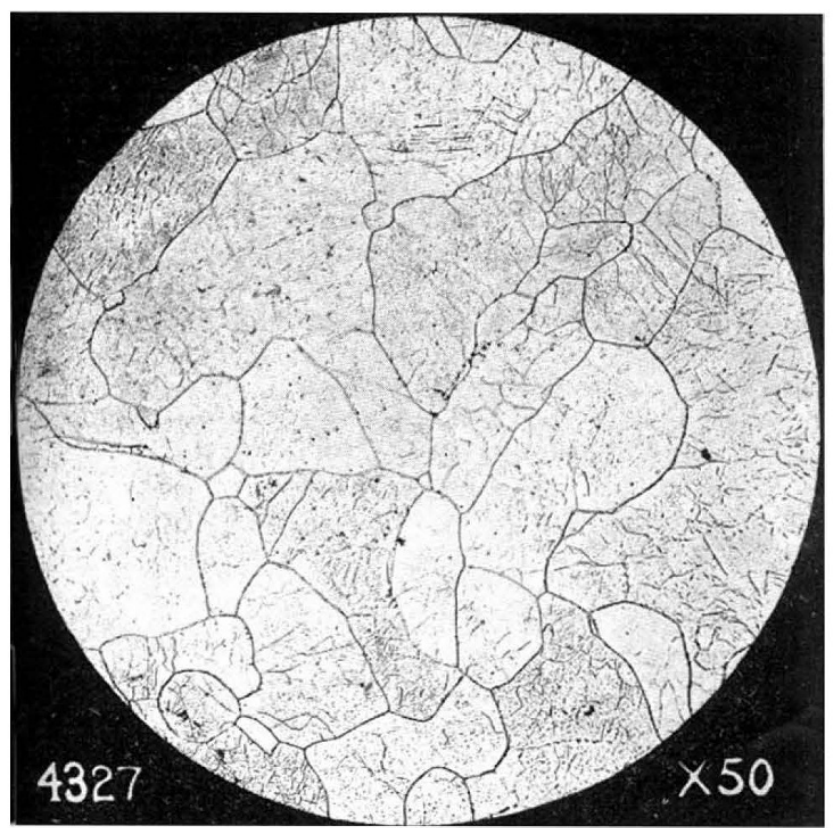

FIG. 1.-Photomicrograph of a specimen from the Delhi iron pillar.

given, there must be added that due for his researches on the transformations of silica at elevated temperatures, which in no inconsiderable manner paved the way for the recent advances in our knowledge of the refractory materials in general.

Sir Robert's concluding remarks are of wide interest and may well be quoted in full :

"In offering my contribution to this distinguished gathering of prominent scientists, who have come from so many countries to attend this Congress, I venture to point out that this very gathering itself affords an obvious testimony to the truth of the saying that ' Science knows no boundaries.'

We are met, here in Paris, the renowned capital of France, and, it may with truth be said, the city wherein, perhaps more than in any other throughout the whole world, science receives most help and most encouragement.

In a memoir which I communicated to the University of Oxford, towards the beginning of this year, I showed an engraving in which was represented one of the greatest scientists of medieval England, Roger Bacon, in the act of presenting a book, the record of his work, to the University of Paris, about the year I250. During the fourteenth and fifteenth centuries Paris was, indeed, the centre of science.

The University of your city was, even then, exercising considerable influence on the universities at that time established in England. I might cite, as an example, Jean Buriden, Rector of the University of Paris, who was one of the founders of modern dynamical science. M. Picard, chief secretary of the Academy of Sciences, has already written, on this subject, a. memoir most carefully and interestingly drawn up, with reference to the facts I have mentioned.

That which was true of the past centuries is still true of the present day. Paris has not lost her ancient renown in the sciences; she still preserves it, and it may very frequently be observed that the great ideas which spread through the world of science are ideas the origin of which may often be traced to distinguished Frenchmen.

I venture to believe that in uttering these sentiments I am expressing, not my own views alone, but those of my colleagues here present, and those, indeed, of the whole world. I trust that France will maintain, in the future, the position which the wisdom of her great men has won for her in the past."

One cannot but be impressed throughout the address by the intimate connexion of the work of French men of science with industrial problems, a liaison which has proved of the greatest importance. A quotation by Percy, in the preface to his classical work on the "Metallurgy of Iron and Steel," from Réaumur, remains as true to-day as it was two hundred years ago: ". . L'utile bien considéré a toujours de curieux, et il est rare que le curieux bien suivi ne mène pas à l'utile. ..."

F. C. T.

\section{The Cierva Auto-Gyro.}

By Prof. L. Bairstow, F.R.S.

A NEW flying machine, quite unlike the normal aeroplane and bearing a strong resemblance to a helicopter, has flown very successfully and excited general interest. It is yet too early to see the full consequences of this notable achievement, but perhaps not too soon to attempt a preliminary statement of what appears to be its general principles, in order to prevent undue expectations.

The auto-gyro has the normal parts of an aeroplane except its wings; the latter are replaced by a screw rotating freely about an ax1s which is nearly vertical in flight. Except when starting, this screw or autogyro, is not mechanically driven, but is maintained in rapid rotation by the play of aerodynamic reactions. The forward motion of the craft is produced by the normal airscrew and engine of an Avro biplane, the body, controls, and under-carriage of which are retained, except that a very large movement is given to the elevators. Ailerons have been fitted to the craft, hut are said to be unnecessary.

No. 2922 , VOL. II 67 